\title{
AJUSTE DE METODOLOGIAS PARA A IDENTIFICAÇÃO DE CULTIVARES DE SOJA QUANTO À TOLERÂNCIA AO GLIFOSATO ${ }^{1}$
}

\author{
WELISON ANDRADE PEREIRA², SUZANA PATRÍCIA LISBOA ${ }^{3}$, DENISE CUNHA FERNANDES DOS SANTOS DIAS ${ }^{4}$, \\ EVELINE MANTOVANI ALVARENGA4, ALUÍZIO BORÉM ${ }^{4}$
}

\begin{abstract}
RESUMO - Os bioensaios constituem numa alternativa prática e eficiente para detecção de sementes de soja geneticamente modificada (GM), tolerante ao glifosato. Contudo, deve ser verificada sua utilização na identificação das sementes quando o lote é de soja GM, ou seja, quando sementes de soja convencional são a minoria. Objetivou-se com este trabalho ajustar a metodologia de dois bioensaios de detecção de sementes de soja GM e testar os melhores protocolos, um de cada bioensaio, na detecção e quantificação de misturas simuladas, contendo genótipos contrastantes quanto à tolerância ao herbicida. Nos bioensaios, foram testadas três umidades do substrato $(2,0 ; 2,5$ e 3,0 vezes o seu peso seco), cinco soluções do herbicida $(0 ; 0,01 ; 0,03 ; 0,06$ e $0,12 \%)$ no método papel umedecido com glifosato e quatro soluções $(0 ; 0,3 ; 0,6$ e $1,2 \%)$ no método pré - embebição de sementes. A umidade 3,0 e solução $0,03 \%$ constituíram o protocolo mais eficiente para detecção no método do papel umedecido. A umidade 2,0 e solução $0,3 \%$ se destacaram no método da pré-embebição das sementes. Foi mais prático e rápido detectar plântulas tolerantes do que plântulas sensíveis em ambos os testes. Em amostras com maior taxa de contaminação, foi mais fácil detectar e mais difícil quantificar misturas com exatidão. Os erros foram relativamente raros considerando os acertos.
\end{abstract}

Termos para indexação: Glycine max, organismo geneticamente modificado, pureza genética.

\section{ADJUSTMENT OF METODOLOGYES TO VERIFICATION OF SOYBEAN CULTIVARS AS THE TOLERANCE TO THE GLYPHOSATE}

\begin{abstract}
Bioassays constitute a practical and efficient alternative for detection of genetically modified soybean seeds (GM) tolerant to gliphosate. However, their use should be analyzed in the identification of seeds when the lot is of GM soybean, in other words, when seeds of conventional soybean are the minority. The objectives of this study were to adjust the methodology of two bioassays to detect GM soybean seeds and to test the best protocols, one of each bioassay, in the detection and quantification of simulated mixtures, containing contrasting genotypes for tolerance to the herbicide. In the bioassays, the following were tested: three moistures of the substratum paper $(2.0 ; 2.5$ and 3.0 times the dry weight), five solutions $(0 ; 0.01 ; 0.03 ; 0.06$ and $0.12 \%)$ in the method moistened paper with herbicide and four solutions $(0 ; 0.3 ; 0.6$ and $1.2 \%)$ in the pre-soak seed method. The moisture 3.0 and solution $0.03 \%$ constituted the most efficient protocol for detection in the moistened paper method. The moisture 2.0 and solution $0.3 \%$ stood out in the pre-soak seed method. It was more
\end{abstract}

${ }^{1}$ Submetido em 09/09/2008. Aceito para publicação em: 13/05/2009.

${ }^{2}$ Doutorando em Genética e Melhoramento, Depto. de Fitotecnia, Universidade Federal de Viçosa, 36570-000 - Viçosa - MG. E-mail: welison.pereira@ufv.br;

${ }^{3}$ Doutoranda em Fitotecnia, Depto. Fitotecnia, Universidade Federal de
Viçosa, 36570-000-Viçosa - MG. E-mail: suzanaplisboa@yahoo.com.br.

${ }^{4}$ Professor Adjunto, Depto. de Fitotecnia, Universidade Federal de Viçosa, 36570-000 - Viçosa - MG. E-mail: dcdias@ufv.br; eveline@ufv.br; borem@ufv.br. 
practical and quicker to detect tolerant seedlings than sensitive seedlings in both tests. In samples with higher contamination rates, it was easier to detect and more difficult to precisely quantify the mixtures. The mistakes were relatively rare considering the successes.

Index terms: Glycine max, modified genetically organism, genetic purity.

\section{INTRODUÇÃO}

O melhoramento genético tem propiciado cultivares altamente produtivas e com diversos perfis. A soja geneticamente modificada (GM) tolerante ao glifosato é uma opção favorável ao plantio direto, que possibilita redução no uso de herbicidas, flexibilidade no controle de plantas daninhas, menor impacto ambiental (Kleba, 1998), entre outros benefícios (Padgette et al., 1995), que convergem para o potencial incremento em produtividade e rentabilidade da lavoura de soja. Por outro lado, a preocupação com pureza genética ganha relevância no mercado sementeiro, tendo em vista a evolução do sistema produtivo e o conseqüente aumento no rigor dos padrões para produção e comercialização de sementes. É presumível que a verificação de cultivares quanto à transgenia venha fazer parte desses padrões, visto a liberação do plantio de soja GM e a exigência de pureza genética.

$\mathrm{Na}$ rotina do laboratório de análise de sementes (LAS), durante a execução da análise física de um lote, alguns procedimentos são utilizados para a verificação de ocorrência de sementes de diferentes cultivares (Brasil, 1992). No que se refere à soja GM tolerante ao glifosato, bioensaios com diferentes princípios vêm sendo publicados no intuito de fornecer uma metodologia confiável para detecção de sementes de soja GM em lotes de sementes de soja não-GM. Entre os bioensaios, todos com bons resultados, podem ser citados: germinação seguida de aplicação do herbicida sobre as plantas (Goggi and Stahr, 1997); pulverização foliar com glifosato pós-germinação (Bevilaqua et al., 2000; Torres et al., 2003); umedecimento do substrato de germinação com solução do herbicida (Bevilaqua et al., 2000; Funguetto et al., 2004; Miranda et al., 2005); identificação com base na atividade de enzimas (Menezes et al., 2004); imersão de sementes em solução do herbicida (Funguetto et al., 2004; Tillmann and West, 2004); pré-embebição de sementes em substrato umedecido com glifosato (Goggi and Stahr, 1997; Funguetto et al., 2004; Tillmann and West, 2004); emergência da plântula em areia, seguida de aplicação do herbicida (Miranda et al., 2006); e, detecção em sistema hidropônico (Bertagnolli et al., 2006).

Nos estudos citados, objetivou-se detectar sementes de soja GM em lotes de soja convencional, mas, não foi verificada a utilização desses métodos na detecção de sementes de soja convencional em lotes de soja GM, o que leva ao questionamento se a eficiência dos bioensaios continua a mesma nesta situação. Esta poderia ser uma indagação do produtor que opta por cultivar a soja tolerante ao herbicida, mas, deseja antes investigar a pureza genética do lote de sementes adquirido. Caso o lote contenha sementes de soja convencional sensível ao herbicida, parte de sua lavoura seria perdida sob a aplicação do glifosato na pós-emergência (Kleba, 1998).

Cunha et al. (2005) compararam o desempenho de diferentes bioensaios para detecção de sementes de soja GM, e concluíram sobre a alta eficiência desses métodos perante às técnicas moleculares em relação ao custo/benefício. Miranda et al. (2005) e Miranda et al. (2006) demonstraram a capacidade de diferentes métodos em detectar e quantificar misturas simuladas, onde os bioensaios confirmaram seu elevado potencial. Pereira et al. (2007) utilizaram os bioensaios na estimativa do fluxo gênico entre uma cultivar de soja GM e uma cultivar de soja convencional sensível ao glifosato e estes bioensaios foram eficientes em possibilitar a identificação das plântulas tolerantes a este herbicida nas amostras analisadas. Considerando a expansão do mercado de sementes de soja GM, é possível que os bioensaios sejam exigidos dentro dos padrões para produção e comercialização de sementes de soja. Assim, ajustes nos bioensaios devem ser investigados com a finalidade de otimizar a capacidade destes testes em identificar sementes GM.

É fato que diferenças acentuadas de potenciais hídricos entre sementes e substrato caracterizam a transferência rápida de água para as sementes, o que pode resultar em danos por embebição (Marcos Filho, 2005). Ao contrário, caso o potencial hídrico da semente seja sutilmente inferior ao do seu ambiente, a embebição se dá de modo menos brusco, o que é favorável à germinação de sementes muito secas ou com menor capacidade de reorganização de suas membranas. Assim, a umidade 
do papel nos bioensaios de detecção de soja GM deve ser analisada.

Objetivou-se com este trabalho: i) ajustar metodologias de bioensaios para detecção de sementes de soja Roundup Ready (RR) quanto à umidade do substrato e a concentração do herbicida na solução; e, ii) avaliar a eficiência de cada bioensaio na detecção e quantificação de misturas simuladas contendo sementes de soja GM e não-GM.

\section{MATERIAL E MÉTODOS}

Os estudos foram conduzidos no Laboratório de Sementes e Melhoramento de Soja, do Departamento de Fitotecnia da Universidade Federal de Viçosa, MG, nos meses de junho e julho de 2007. Foram realizados, preliminarmente, o teste de germinação, peso de 1000 sementes e teor de água (Brasil, 1992), a fim de caracterizar as cultivares estudadas, CD 219 RR (GM) e CD 211, sendo esta última, convencional, sensível ao glifosato.

Para o ajuste das metodologias, as sementes foram submetidas aos bioensaios: germinação de sementes em papel umedecido com glifosato e pré-embebição das sementes em substrato umedecido com solução do herbicida. Estes, detalhadamente descritos a seguir.

Foram avaliadas diferentes soluções e três umidades no substrato: 2,0; 2,5 e 3,0 vezes o peso do papel seco, de agora em diante, referidas como umidades 2,$0 ; 2,5$ e 3,0 , respectivamente. Os bioensaios foram implantados da seguinte forma:

\section{Bioensaio 1 - Germinação em papel umedecido com solução do glifosato}

O substrato para germinação, papel germitest, foi umedecido com água no controle e com soluções do herbicida nas concentrações 0,$01 ; 0,03 ; 0,06$ e $0,12 \%$ do equivalente ácido (e.a.) do herbicida nos demais tratamentos (Miranda et al., 2005). Os rolos de germinação, com 50 sementes cada, foram incubados em câmara de germinação por 7 dias, sob temperatura de $25 \pm 1{ }^{\circ} \mathrm{C}$. Após este período, foram avaliadas as porcentagens de plântulas normais (PNO), plântulas anormais (PAN), plântulas com raízes secundárias (PRS), plântulas com comprimento superior a $15 \mathrm{~cm}$ (PMA15) e comprimento médio de plântulas (CME). $\mathrm{O}$ delineamento experimental adotado foi o inteiramente casualizado em esquema fatorial ( 5 soluções x 3 umidades do substrato), com quatro repetições de 50 sementes.

\section{Bioensaio 2 - Pré-embebição das sementes em papel umedecido com herbicida}

As sementes, em número de 50 por repetição, foram colocadas para pré-embebição em papel germitest umedecido com água para o controle e com soluções do e.a. do herbicida nas concentrações de 0,$3 ; 0,6$ e $1,2 \%$ por 16 horas em câmara de germinação $\left(25 \pm 1^{\circ} \mathrm{C}\right)$. Após este período foram transferidas para substrato umedecido com água destilada nas proporções de 2,0;2,5 e 3,0 vezes o peso do papel para o teste de germinação. As avaliações foram realizadas no $7^{\circ}$ dia da implantação do ensaio, computandose as porcentagens de plântulas normais (PNO), plântulas anormais (PAN), plântulas com raízes secundárias (PRS), plântulas com comprimento superior a 15 centímetros (PMA15) e comprimento médio de plântulas (CME). O delineamento experimental adotado foi o inteiramente casualizado em esquema fatorial (4 soluções x 3 umidades do substrato), com quatro repetições.

\section{Morfologia das plântulas}

Durante a obtenção dos protocolos, buscou-se estudar e caracterizar morfologicamente as plântulas tolerantes e sensíveis ao glifosato quando em presença do herbicida.

\section{Análise estatística}

Os dados foram analisados pelo Sistema de Análises Estatísticas e Genéticas da UFV (Saeg-UFV, 1993), procedendo a análise de variância e o teste de médias de Tukey, ao nível de $5 \%$ de probabilidade. $\mathrm{Na}$ análise, os dados em porcentagem foram transformados em arc-sen $(\mathrm{x} / 100)^{0,5}$, no entanto, para a visualização dos resultados obtidos, foram apresentados nas tabelas os seus valores originais em porcentagem.

A partir da análise estatística, buscou-se obter um protocolo para cada bioensaio, visando a próxima etapa do trabalho. O julgamento das metodologias se baseou na verificação de qual protocolo (concentração do herbicida e umidade do substrato) permite a melhor discriminação dos genótipos quanto a tolerância e sensibilidade ao glifosato.

\section{Quantificação de misturas}

Após a realização da primeira etapa deste estudo (ajuste dos bioensaios), na qual buscou-se o protocolo mais eficiente (melhor umidade e solução) para caracterizar genótipos contrastantes quanto à tolerância ao glifosato, foi executada a segunda etapa desta pesquisa, focada na aplicação destes protocolos como recurso para detecção 
e quantificação de mistura entre cultivares de soja, tolerante e sensível ao herbicida, no mesmo lote. Foram simuladas, sem o conhecimento do analista, quatro níveis de contaminações: $0,1,3$ e $5 \%$ de sementes da cultivar GM entre sementes da cultivar convencional, conforme realizado por Miranda et al. (2005). Adicionalmente, foi simulada a presença de sementes da cultivar convencional como minoria nas misturas, nas proporções de $0,1,3$ e 5 $\%$ de contaminação na cultivar GM. O ensaio contou com quatro repetições de 100 sementes, distribuídas em oito rolos de papel germitest, contendo 50 sementes cada.

Adaptando o método utilizado por Miranda et al. (2006), durante a montagem dos ensaios, foram utilizados croquis, indicando as posições no papel de germinação de todas as sementes de soja, tolerantes ou sensíveis ao glifosato (Figura 1). Deste modo, após a avaliação do analista, foi possível verificar se o que ele considerou como mistura realmente o era. A eficiência do bioensaio foi estimada com base na porcentagem de acertos obtida pelo analista. Para avaliar a eficiência dos bioensaios em possibilitar a detecção de amostras com mistura, o analista assinalou, para cada parcela experimental, a existência ou não de misturas. Na seqüência, para avaliar a acurácia dos bioensaios para a quantificação das misturas, ou seja, determinar a porcentagem exata de contaminação na parcela experimental, o analista preencheu uma planilha, na qual indicou o número de plântulas diferentes da maioria que ele encontrou em cada amostra.



FIGURA 1. Ilustração do croqui adotado para a anotação das posições das sementes no papel de germinação para cada amostra de 50 sementes. Neste caso, a posição de duas sementes diferentes das demais quanto à tolerância ao herbicida, como exemplo.

Após a avaliação do analista, suas conclusões foram corrigidas com base nos croquis experimentais construídos durante a montagem dos bioensaios. Na avaliação da eficiência em detecção de misturas, foram possíveis duas respostas: presença ou ausência de misturas. $\mathrm{Na}$ avaliação da eficiência em quantificar o percentual de contaminação, foram possíveis duas respostas: plântula tolerante ou sensível ao glifosato. Assim, foi obtida a porcentagem de acerto do analista e, na ocorrência de equívoco, a identificação do tipo de erro, sendo dois tipos possíveis:
Falso positivo, quando o analista diagnosticou uma mistura incorretamente; e, falso negativo, situação na qual a mistura não foi percebida.

\section{RESULTADOS E DISCUSSÃO}

Ambas as cultivares apresentaram porcentagem de germinação superior aos $85 \%$ e teor de água inferior aos $11 \%$ (Tabela 1), características indicativas de boa qualidade fisiológica. 
TABELA 1. Porcentagem de germinação (G), peso de 1000 sementes (P1000) e, teor de água (TA) das sementes das cultivares de soja CD211 e CD219.

\begin{tabular}{cccc}
\hline \multirow{2}{*}{ Cultivar } & \multicolumn{3}{c}{ Valores } \\
\cline { 2 - 4 } & $\mathrm{G}(\%)$ & $\mathrm{P} 1000(\mathrm{~g})$ & $\mathrm{TA}(\%)$ \\
\hline CD211 & 86 & 116,23 & 10,2 \\
CD219 & 91 & 127,10 & 10,3 \\
\hline
\end{tabular}

Como em vários outros estudos sobre detecção de sementes de soja tolerante ao herbicida (Goggi and Stahr, 1997, Bevilaqua et al., 2000; Torres et al., 2003; Funguetto et al., 2004; Tillmann and West, 2004, Cunha et al., 2005; Miranda et al., 2005), a diferença marcante entre as cultivares foi a presença e ausência de plântulas normais quando em tratamento contendo o herbicida, tanto para o bioensaio em papel umedecido (Tabelas 2 e 3), quanto para o bioensaio de pré-embebição (Tabelas 6 e 7). O princípio de ambos bioensaios consiste no fato de que o contato entre as sementes de soja convencional com a solução do herbicida (Funguetto et al., 2004; Tillmann and West, 2004; Miranda et al., 2005) resulta em plântulas anormais. Nesta situação de contato com o herbicida, sementes de uma cultivar GM resultam plântulas normais. Neste sentido, esta discussão concentrou em comparar os tratamentos entre si e encontrar a melhor umidade e concentração do herbicida para cada bioensaio, ou seja, a metodologia mais eficiente em distinguir os genótipos em relação à tolerância ao glifosato.

TABELA 2. Porcentagens de plântulas normais (PNO) e de plântulas anormais (PAN) apresentadas pela cultivar CD211, sensível ao glifosato, em função das três umidades $(2,0 ; 2,5$ e 3,0 vezes o peso do substrato seco) no método do substrato umedecido com solução do herbicida em cinco concentrações.

\begin{tabular}{lcccccc}
\hline \multirow{2}{*}{ e. a. ${ }^{1}$} & \multicolumn{3}{c}{ PNO (\%) } & \multicolumn{3}{c}{ PAN (\%) } \\
\cline { 2 - 7 } & 2,0 & 2,5 & 3,0 & 2,0 & 2,5 & 3,0 \\
\hline 0,00 & $82 \mathrm{aB}{ }^{2}$ & $86 \mathrm{aA}$ & $87 \mathrm{aA}$ & $15 \mathrm{bA}$ & $10 \mathrm{bA}$ & $13 \mathrm{bA}$ \\
0,01 & $0 \mathrm{bA}$ & $0 \mathrm{bA}$ & $0 \mathrm{bA}$ & $99 \mathrm{aA}$ & $97 \mathrm{aA}$ & $100 \mathrm{aA}$ \\
0,03 & $0 \mathrm{bA}$ & $0 \mathrm{bA}$ & $0 \mathrm{bA}$ & $96 \mathrm{aA}$ & $98 \mathrm{aA}$ & $98 \mathrm{aA}$ \\
0,06 & $0 \mathrm{bA}$ & $0 \mathrm{bA}$ & $0 \mathrm{bA}$ & $98 \mathrm{aA}$ & $99 \mathrm{aA}$ & $97 \mathrm{aA}$ \\
0,12 & $0 \mathrm{bA}$ & $0 \mathrm{bA}$ & $0 \mathrm{bA}$ & $99 \mathrm{aA}$ & $97 \mathrm{aA}$ & $99 \mathrm{aA}$ \\
\hline Média & & 16,90 & & & 68,70 \\
\hline CV & 11,99 & & & 10,69 \\
\hline
\end{tabular}

${ }^{1}$ Concentração do equivalente ácido do herbicida utilizado na solução do tratamento. ${ }^{2}$ Médias seguidas de mesma letra (maiúscula na linha e minúscula na coluna) não diferem estatisticamente entre si pelo teste Tukey, ao nível de $5 \%$ de probabilidade.
TABELA 3. Porcentagens de plântulas normais (PNO) e de plântulas anormais (PAN) apresentadas pela cultivar CD219, tolerante ao glifosato, em função das três umidades $(2,0 ; 2,5$ e 3,0 vezes o peso do substrato seco) no método do substrato umedecido com solução do herbicida em cinco concentrações.

\begin{tabular}{lcccccr}
\hline & \multicolumn{3}{c}{ PNO (\%) } & \multicolumn{3}{c}{ PAN (\%) } \\
\cline { 2 - 7 } e. a. & 2,0 & 2,5 & 3,0 & 2,0 & 2,5 & 3,0 \\
\hline 0,00 & $94 \mathrm{aA}$ & $90 \mathrm{abA}$ & $88 \mathrm{abA}$ & $06 \mathrm{cA}$ & $10 \mathrm{bcA}$ & $12 \mathrm{cA}$ \\
0,01 & $91 \mathrm{abA}$ & $95 \mathrm{aA}$ & $92 \mathrm{aA}$ & $09 \mathrm{cA}$ & $05 \mathrm{cA}$ & $08 \mathrm{cA}$ \\
0,03 & $90 \mathrm{abA}$ & $83 \mathrm{bA}$ & $86 \mathrm{abA}$ & $10 \mathrm{bcA}$ & $17 \mathrm{bA}$ & $13 \mathrm{bcA}$ \\
0,06 & $81 \mathrm{bA}$ & $87 \mathrm{abA}$ & $78 \mathrm{bA}$ & $19 \mathrm{bAB}$ & $12 \mathrm{bcB}$ & $22 \mathrm{bA}$ \\
0,12 & $61 \mathrm{cA}$ & $40 \mathrm{cB}$ & $33 \mathrm{cB}$ & $40 \mathrm{aC}$ & $58 \mathrm{aB}$ & $67 \mathrm{aA}$ \\
\hline Média & 39,0 & & \multicolumn{3}{c}{20,53} \\
\hline CV & 3,19 & \multicolumn{3}{c}{25,13} \\
\hline
\end{tabular}

${ }^{1}$ Concentração do equivalente ácido do herbicida utilizado na solução do tratamento.

${ }^{2}$ Médias seguidas de mesma letra (maiúscula na linha e minúscula na coluna) não diferem estatisticamente entre si pelo teste Tukey, ao nível de $5 \%$ de probabilidade.

Bioensaio 1 - Germinação em papel umedecido com solução do glifosato

Para a cultivar convencional, a porcentagem de plântulas normais (PNO) observada no controle foi maior nas umidades 2,5 e 3,0, enquanto nos tratamentos contendo herbicida, o desenvolvimento de plântulas normais foi inibido totalmente, independente do nível de umidade (Tabela 2), em acordo com Bevilaqua et al. (2000), Tillmann and West (2004) e Cunha et al. (2005). A cultivar GM apresentou comportamento indiferente às umidades em relação à porcentagem de plântulas normais, exceto para o nível de $0,12 \%$ e.a., onde se observou reduzida taxa de plântulas normais nas umidades 2,5 e 3,0. Na umidade 2,0 , as concentrações 0,06 e $0,12 \%$ e.a. reduziram a porcentagem de plântulas normais (Tabela 3).

As umidades testadas não interferiram na porcentagem de plântulas anormais (PAN) da cultivar convencional e a concentração de $0,01 \%$ do herbicida foi suficiente para a incidência de $100 \%$ de anormalidade, evidenciando a sensibilidade desta cultivar para com o herbicida (Tabela 2). No grupo controle, um maior número de plântulas da cultivar convencional emitiu raízes secundárias (PRS) na umidade 3,0 quando comparada à umidade 2,0 , enquanto que nos tratamentos contendo glifosato, 
verificou-se ausência de PRS (Tabela 4). Funguetto et al. (2004), verificaram inibição completa na formação de raízes secundárias neste tipo de bioensaio, independente da concentração do herbicida, e consideraram as raízes secundárias como uma boa característica para diferenciar as cultivares GM das não-GM. Considerando a cultivar GM, a solução $0,12 \%$ do e.a. do herbicida afetou significativamente o percentual de raízes secundárias em todos os níveis de umidade, com a maior queda na umidade 3,0 (Tabela 5). Isto se justifica pelo fato de que a introdução do gene $c p 4$ epsps no genoma da planta lhe confere tolerância ao herbicida e não resistência. Deste modo, elevadas concentrações do herbicida podem afetar o desenvolvimento tanto de plântulas de cultivares convencionais quanto de geneticamente modificadas para este caracter.

TABELA 4. Porcentagem de plântulas com raízes secundárias (PRS), comprimento médio de plântulas (CME) em centímetros e porcentagem de plântulas maiores que 15 centímetros (PMA15) apresentadas pela cultivar CD211, sensível ao glifosato, em função das três umidades $(2,0 ; 2,5$ e 3,0 vezes o peso do substrato seco) no método do substrato umedecido com solução do herbicida em cinco concentrações.

\begin{tabular}{|c|c|c|c|c|c|c|c|c|c|}
\hline \multirow{2}{*}{$\%$ e. a. ${ }^{1}$} & \multicolumn{3}{|c|}{ PRS (\%) } & \multicolumn{3}{|c|}{$\mathrm{CME}(\mathrm{cm})$} & \multicolumn{3}{|c|}{ PMA15 (\%) } \\
\hline & 2,0 & 2,5 & 3,0 & 2,0 & 2,5 & 3,0 & 2,0 & 2,5 & 3,0 \\
\hline 0,00 & $90 \mathrm{aB}$ & $91 \mathrm{aAB}$ & $94 \mathrm{aA}$ & $12,4 \mathrm{aB}$ & $13,3 \mathrm{aA}$ & $13,2 \mathrm{aA}$ & $65 \mathrm{aB}$ & $77 \mathrm{aA}$ & $76 \mathrm{aA}$ \\
\hline 0,01 & ObA & ObA & ObA & $0,0 \mathrm{bA}$ & $0,0 \mathrm{bA}$ & $0,0 \mathrm{bA}$ & $0,0 \mathrm{bA}$ & $0,0 \mathrm{bA}$ & $0,0 \mathrm{bA}$ \\
\hline 0,03 & ObA & ObA & ObA & $0,0 \mathrm{bA}$ & $0,0 \mathrm{bA}$ & $0,0 \mathrm{bA}$ & $0,0 \mathrm{bA}$ & $0,0 \mathrm{bA}$ & $0,0 \mathrm{bA}$ \\
\hline 0,06 & ObA & ObA & ObA & $0,0 \mathrm{bA}$ & $0,0 \mathrm{bA}$ & $0,0 \mathrm{bA}$ & $0,0 \mathrm{bA}$ & $0,0 \mathrm{bA}$ & $0,0 \mathrm{bA}$ \\
\hline 0,12 & ObA & ObA & ObA & $0,0 \mathrm{bA}$ & $0,0 \mathrm{bA}$ & $0,0 \mathrm{bA}$ & $0,0 \mathrm{bA}$ & $0,0 \mathrm{bA}$ & $0,0 \mathrm{bA}$ \\
\hline Média & & 18,33 & & & 2,5 & & & 14,49 & \\
\hline $\mathrm{CV}$ & & 9,89 & & & 13,5 & & & 34,39 & \\
\hline
\end{tabular}

${ }^{1}$ Concentração do equivalente ácido do herbicida utilizado na solução do tratamento.

${ }^{2}$ Médias seguidas de mesma letra (maiúscula na linha e minúscula na coluna) não diferem estatisticamente entre si pelo teste Tukey, ao nível de $5 \%$ de probabilidade.

TABELA 5. Porcentagem de plântulas com raízes secundárias (PRS), comprimento médio de plântulas (CME) em centímetros e porcentagem de plântulas maiores que 15 centímetros (PMA15) apresentadas pela cultivar CD219, tolerante ao glifosato, em função das três umidades $(2,0 ; 2,5$ e 3,0 vezes o peso do substrato seco) no método do substrato umedecido com solução do herbicida em cinco concentrações.

\begin{tabular}{|c|c|c|c|c|c|c|c|c|c|}
\hline \multirow{2}{*}{$\%$ e. a. ${ }^{1}$} & \multicolumn{3}{|c|}{ PRS (\%) } & \multicolumn{3}{|c|}{ CME (cm) } & \multicolumn{3}{|c|}{ PMA15 (\%) } \\
\hline & 2,0 & 2,5 & 3,0 & 2,0 & 2,5 & 3,0 & 2,0 & 2,5 & 3,0 \\
\hline 0,00 & $98 \mathrm{aA}$ & $97 \mathrm{aA}$ & $96 \mathrm{aA}$ & $11,1 \mathrm{aB}$ & $12,7 \mathrm{aA}$ & $13,2 \mathrm{aA}$ & $49 \mathrm{aC}$ & $67 \mathrm{aB}$ & $74 \mathrm{aA}$ \\
\hline 0,01 & $98 \mathrm{aA}$ & $99 \mathrm{aA}$ & $96 \mathrm{aA}$ & $8.7 \mathrm{bB}$ & $8,7 \mathrm{bB}$ & $9,5 \mathrm{bA}$ & $16 \mathrm{bB}$ & $14,7 \mathrm{bB}$ & $29 \mathrm{bA}$ \\
\hline 0,03 & $93 \mathrm{aA}$ & $93 \mathrm{aA}$ & $95 \mathrm{aA}$ & $7,6 \mathrm{cA}$ & $7,1 \mathrm{cA}$ & $7,3 \mathrm{cA}$ & $0,5 \mathrm{cA}$ & $0 \mathrm{cA}$ & $1,2 \mathrm{cA}$ \\
\hline 0,06 & $92 \mathrm{aA}$ & $92 \mathrm{aA}$ & $90 \mathrm{aA}$ & $4,5 \mathrm{dA}$ & $4,7 \mathrm{dA}$ & $4,5 \mathrm{dA}$ & $0 \mathrm{cA}$ & $0 \mathrm{cA}$ & $0 \mathrm{cA}$ \\
\hline 0,12 & $71 \mathrm{bA}$ & $44 \mathrm{bB}$ & $33 \mathrm{bC}$ & $4,0 \mathrm{dA}$ & $4,0 \mathrm{dA}$ & $4,0 \mathrm{dA}$ & $0 \mathrm{cA}$ & $0 \mathrm{cA}$ & $0 \mathrm{cA}$ \\
\hline Média & & 85,7 & & & 7,41 & & & 16,79 & \\
\hline $\mathrm{CV}$ & & 5,49 & & & 5,11 & & & 23,35 & \\
\hline
\end{tabular}

${ }^{1}$ Concentração do equivalente ácido do herbicida utilizado na solução do tratamento.

${ }^{2}$ Médias seguidas de mesma letra (maiúscula na linha e minúscula na coluna) não diferem estatisticamente entre si pelo teste Tukey, ao nível de $5 \%$ de probabilidade.

Nota-se, a partir das tabelas 4 e 5 que no método do substrato umedecido com solução do herbicida, as umidades 2,5 e 3,0 favoreceram o comprimento médio das plântulas (CME) de ambas as cultivares no tratamento controle, e o aumento da concentração do herbicida reduziu o comprimento médio das plântulas da cultivar GM. Na concentração 0,01 $\%$ e umidade 3,0 , a cultivar GM apresentou um número superior de plântulas maiores que $15 \mathrm{~cm}$ (PMA15), enquanto que a solução $0,03 \%$, independente da umidade, inibiu a ocorrência de PMA15. 
Neste método, a utilização da umidade de 3,0 vezes o peso do substrato seco permitiu o melhor desempenho das plântulas de soja. Como o princípio dos bioensaios se baseia no melhor desempenho das plântulas, adotou-se como protocolo a umidade 3,0. Em relação à concentração, 0,01 $\%$ do e.a. inibiu o desenvolvimento de plântulas da cultivar convencional, mas essas plântulas chegaram a emitir os primeiros sinais de raízes secundárias, podendo levar a equívocos na interpretação. Por outro lado, como também relatado por Cunha et al. (2005), concentrações mais altas do herbicida, como 0,06 e $0,12 \%$ do e.a. causam prejuízos também ao desenvolvimento das plântulas da cultivar GM, como, aumento na taxa de plântulas anormais, redução na emissão de raízes secundárias e no comprimento médio de plântula (Tabelas 3 e 5). Portanto, para este bioensaio, a concentração 0,03 \% e a umidade 3,0 constituíram o protocolo mais eficiente para a caracterização das plântulas em relação à tolerância ou sensibilidade ao herbicida glifosato.

\section{Bioensaio 2 - Pré-embebição das sementes em papel umedecido com herbicida}

No tratamento controle, as cultivares tolerante e sensível ao glifosato apresentaram porcentagens similares de plântulas normais nas diferentes umidades (Tabelas 6 e 7). Na presença do herbicida, a umidade 2,0 se destacou pelo fato de que as plântulas da cultivar GM não foram prejudicadas nem nas mais altas concentrações do herbicida $(0,6$ e $1,2 \%$ e.a. $)$ e, indiferentemente às umidades 2,$0 ; 2,5$ e 3,0, o tratamento 0,3 \% não prejudicou a ocorrência de plântulas normais (PNO) nesta cultivar (90, 88 e $86 \%$, respectivamente).

TABELA 6. Porcentagens de plântulas normais (PNO) e de plântulas anormais (PAN) apresentadas pela cultivar CD211, sensível ao glifosato, em função das três umidades $(2,0 ; 2,5$ e 3,0 vezes o peso do substrato seco) no método de pré-embebição das sementes em substrato umedecido com solução do herbicida em quatro concentrações.

\begin{tabular}{lcccccc}
\hline \multirow{2}{*}{ \% e. a. ${ }^{1}$} & \multicolumn{3}{c}{ PNO $(\%)$} & \multicolumn{2}{c}{ PAN $(\%)$} \\
\cline { 2 - 6 } & 2,0 & 2,5 & 3,0 & 2,0 & 2,5 & 3,0 \\
\hline 0,00 & $88 \mathrm{aA}^{2}$ & $89 \mathrm{aA}$ & $87 \mathrm{aA}$ & $11 \mathrm{cA}$ & $09 \mathrm{bA}$ & $11 \mathrm{bA}$ \\
0,30 & $0 \mathrm{bA}$ & $0 \mathrm{bA}$ & $0 \mathrm{bA}$ & $100 \mathrm{aA}$ & $100 \mathrm{aA}$ & $96 \mathrm{aA}$ \\
0,60 & $0 \mathrm{bA}$ & $0 \mathrm{bA}$ & $0 \mathrm{bA}$ & $98 \mathrm{abA}$ & $96 \mathrm{aA}$ & $98 \mathrm{aA}$ \\
1,20 & $0 \mathrm{bA}$ & $0 \mathrm{bA}$ & $0 \mathrm{bA}$ & $94 \mathrm{bB}$ & $99 \mathrm{aA}$ & $97 \mathrm{aAB}$ \\
\hline Média & \multicolumn{7}{c}{} & 75,45 & \\
\hline $\mathrm{CV}$ & & 22 & & 3,78 \\
\hline
\end{tabular}

${ }^{1}$ Concentração do equivalente ácido do herbicida utilizado na solução do tratamento. ${ }^{2}$ Médias seguidas de mesma letra (maiúscula na linha e minúscula na coluna) não diferem estatisticamente entre si pelo teste Tukey, ao nível de $5 \%$ de probabilidade.

TABELA 7. Porcentagens de plântulas normais (PNO) e de plântulas anormais (PAN) apresentadas pela cultivar CD219, tolerante ao glifosato, em função das três umidades $(2,0 ; 2,5$ e 3,0 vezes o peso do substrato seco) no método de pré-embebição das sementes em substrato umedecido com solução do herbicida em quatro concentrações.

\begin{tabular}{lcccccc}
\hline \multirow{2}{*}{$\%$ e. a. $^{1}$} & \multicolumn{3}{c}{ PNO $(\%)$} & \multicolumn{3}{c}{ PAN (\%) } \\
\cline { 2 - 7 } & 2,0 & 2,5 & 3,0 & 2,0 & 2,5 & 3,0 \\
\hline 0,00 & $87 \mathrm{aA}$ & $90 \mathrm{aA}$ & $87 \mathrm{aA}$ & $13 \mathrm{aA}$ & $09 \mathrm{cA}$ & $11 \mathrm{bA}$ \\
0,30 & $90 \mathrm{aA}$ & $88 \mathrm{abA}$ & $86 \mathrm{aA}$ & $10 \mathrm{aA}$ & $13 \mathrm{bcA}$ & $13 \mathrm{bA}$ \\
0,60 & $90 \mathrm{aA}$ & $77 \mathrm{bcB}$ & $79 \mathrm{aB}$ & $09 \mathrm{aB}$ & $23 \mathrm{abA}$ & $20 \mathrm{bA}$ \\
1,20 & $83 \mathrm{aA}$ & $74 \mathrm{cB}$ & $66 \mathrm{bB}$ & $17 \mathrm{aB}$ & $25 \mathrm{aAB}$ & $34 \mathrm{aA}$ \\
\hline Média & \multicolumn{7}{c}{82,79} & 16,12 & 31,90 \\
\hline CV & \multicolumn{7}{c}{6,41} & & \\
\hline
\end{tabular}

${ }^{1}$ Concentração do equivalente ácido do herbicida utilizado na solução do tratamento. ${ }^{2}$ Médias seguidas de mesma letra (maiúscula na linha e minúscula na coluna) não diferem estatisticamente entre si pelo teste Tukey, ao nível de $5 \%$ de probabilidade. 
Para porcentagem de plântulas com raízes secundárias (PRS), a umidade 3,0 foi mais favorável ao desenvolvimento dessas raízes pela cultivar convencional no tratamento controle quando comparada com a umidade 2,0 (Tabela 8). Por outro lado, a umidade 2,0, em combinação com as diferentes concentrações do herbicida, não causou prejuízos à cultivar GM (Tabela 9).

TABELA 8. Porcentagens de plântulas com raízes secundárias (PRS), comprimento médio de plântulas (CME) em centímetros e porcentagem de plântulas maiores que 15 centímetros (PMA15) apresentadas pela cultivar CD211, sensível ao glifosato, em função das três umidades $(2,0 ; 2,5$ e 3,0 vezes o peso do substrato seco) no método de pré-embebição das sementes em substrato umedecido com solução do herbicida em quatro concentrações.

\begin{tabular}{lccccccccc}
\hline \multirow{2}{*}{$\%$ e. a. ${ }^{1}$} & \multicolumn{3}{c}{ PRS $(\%)$} & \multicolumn{3}{c}{ CME $(\mathrm{cm})$} & \multicolumn{3}{c}{ PMA15 (\%) } \\
\cline { 2 - 10 } & 2,0 & 2,5 & 3,0 & 2,0 & 2,5 & 3,0 & 2,0 & 2,5 & 3,0 \\
\hline 0,00 & $92 \mathrm{aB}$ & $95 \mathrm{aAB}$ & $96 \mathrm{aA}$ & $14,1 \mathrm{aA}$ & $14,09 \mathrm{aA}$ & $14,2 \mathrm{aA}$ & $89 \mathrm{aA}$ & $87 \mathrm{aA}$ & $89 \mathrm{aA}$ \\
0,30 & $0 \mathrm{bA}$ & $0 \mathrm{bA}$ & $0 \mathrm{bA}$ & $0 \mathrm{bA}$ & $0 \mathrm{bA}$ & $0 \mathrm{bA}$ & $0 \mathrm{bA}$ & $0 \mathrm{bA}$ & $0 \mathrm{bA}$ \\
0,60 & $0 \mathrm{bA}$ & $0 \mathrm{bA}$ & $0 \mathrm{bA}$ & $0 \mathrm{bA}$ & $0 \mathrm{bA}$ & $0 \mathrm{bA}$ & $0 \mathrm{bA}$ & $0 \mathrm{bA}$ & $0 \mathrm{bA}$ \\
1,20 & $0 \mathrm{bA}$ & $0 \mathrm{bA}$ & $0 \mathrm{bA}$ & $0 \mathrm{bA}$ & $0 \mathrm{bA}$ & $0 \mathrm{bA}$ & $0 \mathrm{bA}$ & $0 \mathrm{bA}$ & $0 \mathrm{bA}$ \\
\hline Média & \multicolumn{3}{c}{23,54} & & 3,54 & & & 22,07 \\
\hline CV & & & & 4,94 & & & 11,46 \\
\hline
\end{tabular}

${ }^{1}$ Concentração do equivalente ácido do herbicida utilizado na solução do tratamento. ${ }^{2}$ Médias seguidas de mesma letra (maiúscula na linha e minúscula na coluna) não diferem estatisticamente entre si pelo teste Tukey, ao nível de $5 \%$ de probabilidade.

TABELA 9. Porcentagens de plântulas com raízes secundárias (PRS), comprimento médio de plântulas (CME) em centímetros e porcentagem de plântulas maiores que 15 centímetros (PMA15) apresentadas pela cultivar CD219, tolerante ao glifosato, em função das três umidades $(2,0 ; 2,5$ e 3,0 vezes o peso do substrato seco) no método de pré-embebição das sementes em substrato umedecido com solução do herbicida em quatro concentrações.

\begin{tabular}{|c|c|c|c|c|c|c|c|c|c|}
\hline \multirow{2}{*}{$\%$ e. a. ${ }^{1}$} & \multicolumn{3}{|c|}{ PRS (\%) } & \multicolumn{3}{|c|}{ CME (\%) } & \multicolumn{3}{|c|}{ PMA15 (\%) } \\
\hline & 2,0 & 2,5 & 3,0 & 2,0 & 2,5 & 3,0 & 2,0 & 2,5 & 3,0 \\
\hline 0,00 & $95 \mathrm{aA}$ & $97 \mathrm{aA}$ & $95 \mathrm{aA}$ & $13,9 \mathrm{aA}$ & $14,2 \mathrm{aA}$ & $14,7 \mathrm{aA}$ & $85,5 \mathrm{aA}$ & $88,4 \mathrm{aA}$ & $96,6 \mathrm{aA}$ \\
\hline 0,30 & $97 \mathrm{aA}$ & $96 \mathrm{aA}$ & $95 \mathrm{aA}$ & $12,1 \mathrm{bA}$ & $10,5 \mathrm{bB}$ & $10,6 \mathrm{bB}$ & $61,1 \mathrm{bA}$ & $37,9 \mathrm{bB}$ & $39,0 \mathrm{bB}$ \\
\hline 0,60 & $95 \mathrm{aA}$ & $93 \mathrm{aA}$ & $89 \mathrm{aA}$ & $8,7 \mathrm{cA}$ & $6,9 \mathrm{cB}$ & $7,9 \mathrm{cA}$ & $14,2 \mathrm{cA}$ & $2,1 \mathrm{cA}$ & $4,9 \mathrm{cA}$ \\
\hline 1,20 & $90 \mathrm{aA}$ & $81 \mathrm{bB}$ & $78 \mathrm{bB}$ & $6,6 \mathrm{dA}$ & $5,6 \mathrm{cAB}$ & $5,5 \mathrm{~dB}$ & $1,16 \mathrm{cA}$ & $0,6 \mathrm{cA}$ & $0 \mathrm{cA}$ \\
\hline Média & & 91,54 & & & 9,81 & & & 35,99 & \\
\hline $\mathrm{CV}$ & & 4,05 & & & 6,14 & & & 21,36 & \\
\hline
\end{tabular}

${ }^{1}$ Concentração do equivalente ácido do herbicida utilizado na solução do tratamento. ${ }^{2}$ Médias seguidas de mesma letra (maiúscula na linha e minúscula na coluna) não diferem estatisticamente entre si pelo teste Tukey, ao nível de $5 \%$ de probabilidade.

$\mathrm{Na}$ ausência do herbicida, as umidades não fizeram diferença para a cultivar convencional em relação ao comprimento médio de plântulas (CME) e porcentagem de plântulas com comprimento superior aos $15 \mathrm{~cm}$ (PMA15) (Tabela 8), ao contrário do ocorrido para a cultivar GM, onde os maiores comprimentos nos tratamentos 0,3 e 1,2 $\%$ foram encontrados quando utilizada a umidade 2,0 (Tabela 9). De acordo com estes resultados, o aumento na concentração do herbicida reduziu a taxa de plântulas com comprimento superior aos $15 \mathrm{~cm}$, contudo, na concentração
$0,3 \%$ do herbicida, ocorreu alta taxa de plântulas maiores que $15 \mathrm{~cm}$ na umidade 2,0 (Tabela 9). Funguetto et al. (2004) também observaram que soluções do herbicida, em certas concentrações, reduziram o comprimento total de plântulas da cultivar GM.

Considerando os desempenhos das plântulas de ambas as cultivares, concluiu-se que o melhor protocolo para este bioensaio foi a combinação da concentração $0,3 \%$ e.a. e a umidade 2,0. O excesso do herbicida causou perdas ao desenvolvimento da cultivar tolerante. Como esta cultivar 
expressa a enzima 5-enolpiruvilshiquimato-3-fosfatosintase (EPSPS), naturalmente encontrada nos vegetais, e a alternativa bacteriana (CP4 EPSPS) (Kleba, 1998), a EPSPS originalmente vegetal é inibida pelo glifosato, o que pode justificar as perdas em comprimento, normalidade e emissão de raízes secundárias por sementes desta cultivar.

De acordo com os dados das tabelas 7 e 9, a umidade 2,0 favoreceu a ocorrência de plântulas normais, emissão de raízes secundárias e o crescimento em comprimento das plântulas da cultivar GM. Sementes com teores de água inferiores a $11 \%$ são mais sensíveis a injúrias por embebição rápida (Marcos Filho, 2005). Assim, é possível que este seja o motivo do melhor desempenho das plântulas na umidade de 2,0 vezes o peso do papel seco neste bioensaio.

\section{Morfologia das plântulas}

Os perfis morfológicos das plântulas tolerantes (Figura 2a) e sensíveis (Figura 2b) ao herbicida foram analisados, sendo os mesmos para ambos os bioensaios. Sob exposição ao herbicida, as plântulas da cultivar GM apresentaram desenvolvimento normal, com a emissão de raiz primária e raízes secundárias, indicando o potencial para formação de plantas (Figura 2c). A explicação é a presença da enzima CP4 EPSPS que possibilita à plântula não sofrer os efeitos negativos causados pelo herbicida (Kruse et al., 2000). Por outro lado, plântulas da cultivar convencional, sensível ao glifosato, caracterizam-se pela ausência de raízes secundárias e, na maioria das vezes, nem sinal de sua emissão; sua raiz primária apresenta engrossamento relativamente ao seu comprimento (Funguetto et al., 2004), normalmente não passando dos $5 \mathrm{~cm}$ (Figura 2d). O glifosato inibe a enzima EPSPS ao se ligar e inativar o complexo intermediário EPSPS-S3P (shiquimato-3-fosfato). Nesta condição, a reação catalítica S3P + PEP (fosfoenolpiruvato), sob ação da EPSPS não é realizada, e o composto EPSP não é formado. Como resultado, ocorre o bloqueio na rota metabólica da síntese dos aminoácidos fenilalanina, tirosina e triptofano. $\mathrm{O}$ EPSP é também precursor de outros compostos aromáticos importantes como vitaminas ( $\mathrm{K}$ e E), hormônios (auxina, etileno), alcalóides, lignina, antocianina entre outros produtos secundários (Kruse et al., 2000). É provável que a redução de hormônios de crescimento, como auxina e etileno, tenha afetado o desenvolvimento de raízes de plântulas normais neste estudo.


FIGURA 2. Padrões morfológicos das plântulas de soja. (a) Cultivar de soja tolerante ao glifosato; (b) cultivar de soja sensível ao glifosato; (c) amostra da cultivar convencional contendo uma plântula tolerante ao herbicida; (d) amostra de cultivar de soja tolerante ao glifosato contendo quatro plântulas sensíveis (em destaque); (e) amostra de situação iminente de erro de avaliação. Contornadas em vermelho, plântulas anormais sensíveis ao glifosato; contornadas em branco, plântulas anormais tolerantes; (f) caracterização das plântulas: plântulas sensíveis ao glifosato na metade superior da figura e de plântulas tolerantes ao herbicida, mas, anormais na parte inferior. A tarja branca indica $1 \mathrm{~cm}$. 
Uma limitação dos bioensaios para verificação de cultivares quanto à tolerância ao glifosato reside no fato de que o êxito desses testes depende da qualidade dos lotes de sementes (Miranda et al., 2005). Mesmo aqueles com alta qualidade fisiológica geram plântulas anormais. É presumível então, que apareça a dificuldade em distinguir a anormalidade causada pelo herbicida da anormalidade resultante de outras causas. Assim, erros tipo falsonegativo (não percepção da mistura) podem ocorrer numa quantificação de plântulas tolerantes no meio de plântulas sensíveis, enquanto, erros tipo falso-positivo (percepção equivocada de mistura) podem surgir na quantificação de plântulas sensíveis no meio de plântulas tolerantes (Figura 2e). Por isso, buscou-se caracterizar as anormalidades causadas pelo herbicida.

Anormalidades causadas pelo herbicida são particulares: ausência de raízes secundárias (Goggi and Stahr, 1997; Funguetto et al., 2004; Cunha et al., 2005), redução no comprimento de raiz primária e seu engrossamento (Funguetto et al., 2004), sinal evidente de paralisação do desenvolvimento (Figura 2f). Anormalidades por outras causas exibem diferentes padrões como: hipocótilo quebrado, sinais de ataque por insetos, raiz primária retorcida, delgada ou com sua extremidade danificada, sinais de deterioração, e presença de raízes secundárias, mesmo que pouco desenvolvidas (Figura 2f). Com base no exposto, a anormalidade das plântulas não pode ser adotada de forma generalizada como padrão para a identificação de sementes convencionais em um bioensaio de detecção de sementes de soja GM, mas sim, faz-se necessária uma análise conjunta dos caracteres morfológicos para posterior conclusão.

\section{Quantificação de misturas}

Os resultados da avaliação da eficiência dos protocolos na detecção e quantificação de misturas em amostras de sementes convencionais, contendo ou não sementes da cultivar GM, e amostras de sementes da cultivar GM, contendo ou não, sementes da cultivar convencional são apresentados na Tabela 10. Os dados estão apresentados em porcentagem de acertos.

TABELA 10. Resultado em porcentagem de acertos da avaliação da eficiência dos métodos Papel Umedecido com Herbicida (PUH) e Pré-Embebição de Sementes (PES) para deteç̧ão e quantificação de misturas de sementes geneticamente modificadas (GM) entre sementes convencionais e vice-versa.

\begin{tabular}{|c|c|c|c|c|c|c|c|c|}
\hline \multirow{3}{*}{ Métodos } & \multicolumn{8}{|c|}{ Eficiência para detecção de misturas (\%) } \\
\hline & \multicolumn{4}{|c|}{ Sementes convencionais contaminadas } & \multicolumn{4}{|c|}{ Sementes GM contaminadas } \\
\hline & 0 & 1 & 3 & 5 & 0 & 1 & 3 & 5 \\
\hline PUH & 100 & 100 & 100 & 100 & $50(\mathrm{FPs})^{2}$ & 100 & 100 & 100 \\
\hline \multirow[t]{3}{*}{ PES } & 100 & $75(\mathrm{FN})^{3}$ & 100 & 100 & $75(\mathrm{FP})$ & $75(\mathrm{FN})$ & 100 & 100 \\
\hline & \multicolumn{8}{|c|}{ Eficiência para quantificação de misturas (\%) } \\
\hline & 0 & 1 & 3 & 5 & 0 & 1 & 3 & 5 \\
\hline PUH (TE) ${ }^{1}$ & - & - & $1 \mathrm{FP}$ & $1 \mathrm{FP}$ & $3 \mathrm{FP}$ & $2 \mathrm{FP}$ & $1 \mathrm{FP}, 1 \mathrm{FN}$ & $2 \mathrm{FP}$ \\
\hline Acerto $(\%)$ & 100 & 100 & 99,75 & 99,75 & 99,25 & 99,5 & 99,5 & 99,5 \\
\hline PES (TE) & - & $1 \mathrm{FN}$ & $1 \mathrm{FN}$ & $1 \mathrm{FN}, 2 \mathrm{FP}$ & $1 \mathrm{FP}$ & $1 \mathrm{FP}, 1 \mathrm{FN}$ & - & $1 \mathrm{FN}$ \\
\hline Acerto $(\%)$ & 100 & 99,75 & 99,75 & 99,25 & 99,75 & 99,5 & 100 & 99,75 \\
\hline
\end{tabular}

${ }^{1}$ TE - Tipo de erro.

${ }^{2} \mathrm{FP}$ - Falso positivo, afirmação de presença na ausência.

${ }^{3} \mathrm{FN}$ - Falso negativo, afirmação de ausência na presença.

No que se refere à detecção, os melhores resultados foram obtidos na identificação da presença de sementes da cultivar GM, entre sementes da cultivar convencional. No bioensaio papel umedecido com herbicida, o analista obteve $100 \%$ de acertos nas quatro situações: $0,1,3$ e $5 \%$ de contaminação. No bioensaio pré-embebição, uma parcela contendo $1 \%$ de mistura não foi corretamente avaliada, ocorrendo o erro tipo falso-negativo, ou seja, o analista considerou que não havia mistura. Neste caso, a semente da cultivar GM propositalmente colocada nesta repetição não germinou, e logo, acabou não sendo detectada. Este tipo de erro foi anunciado e também relatado por Miranda et al. (2005). 
$\mathrm{Na}$ verificação de amostras de sementes da cultivar GM contendo sementes da cultivar convencional, erros dos tipos falso-negativo e falso-positivo ocorreram. Discute-se que ambos surgiram de interpretações equivocadas porque amostras de sementes de soja GM apresentam plântulas anormais, as quais podem ser confundidas com plântulas anormais de uma cultivar sensível ao glifosato. A experiência do analista em caracterizar as plântulas anormais de cada cultivar dita o êxito do teste. Na Figura 2c, verifica-se uma amostra de plântulas de soja convencional contendo uma plântula tolerante ao herbicida. Na figura 2 d, é apresentada uma parcela experimental, na qual existem quatro plântulas, em destaque, de cultivar sensível ao herbicida. É notável a maior praticidade visual em detectar, numa parcela experimental, a presença de plântulas da cultivar tolerante entre plântulas de cultivar sensível (Figuras 2c, 2d).

Na quantificação de misturas, ocorreram 20 erros de interpretação. Destes, 7 na verificação de sementes de soja GM entre sementes de soja convencional (papel umedecido: 2 erros e pré-embebição: 5 erros); na verificação de sementes da cultivar sensível entre sementes da cultivar tolerante, ocorreram 13 equívocos (papel umedecido: 9 erros e préembebição: 4 erros). Entretanto, estes erros não abalaram a credibilidade dos bioensaios, visto que foram identificadas corretamente 6.380/6.400 plântulas, uma acurácia de 99,69 $\%$ de acerto.

Em acordo com Miranda et al. (2006), notou-se que foi mais fácil e prático detectar a existência de mistura em amostras com maior taxa de contaminação. Isso é coerente, pois, quanto mais sementes de outras cultivares existirem em uma amostra, mais provável é que se encontre pelo menos uma. Também de acordo com Miranda et al. (2006), foi mais difícil quantificar com exatidão as misturas com mais sementes contaminantes. Isso se justifica pelo fato de que quanto maior for a quantia de sementes de outra cultivar numa amostra, mais provável é que pelo menos uma não seja encontrada.

\section{CONCLUSÕES}

- Os bioensaios de umedecimento do substrato de germinação e de pré-embebição das sementes apresentam elevado potencial para a detecção e quantificação de misturas, e podem constituir em eficientes testes para identificação de cultivares na rotina do LAS.

- Em amostras com maior taxa de contaminação é maior a acurácia em detectar e menor em quantificar misturas, sendo, contudo, os erros raros em relação aos acertos.

- Identificar plântulas tolerantes entre plântulas sensíveis ao glifosato é mais prático do que identificar plântulas sensíveis entre plântulas tolerantes, mas, em ambas situações, os bioensaios são eficientes.

- Os ajustes de umidade do substrato e concentração do herbicida contribuem para o êxito nos estudos de detecção e quantificação de misturas.

\section{AGRADECIMENTOS}

Ao CNPq pela concessão de recursos para a realização desta pesquisa e de bolsa de estudos ao primeiro autor.

\section{REFERÊNCIAS}

BEVILAQUA, G.A.P.; BONATO, E.R.; ROMAN, E.S. Identificação de soja tolerante a glyphosate através do teste de germinação. Revista Brasileira de Herbicidas, v.1, n.3, p.261-265, 2000.

BERTAGNOLLI, C.M.; TILLMANN, M.A.A.; VILLELA, F.A. Sistema hidropônico com uso de solução de herbicida na detecção de soja geneticamente modificada resistente ao glifosato. Revista Brasileira de Sementes, v.28, n.2, p.182192, 2006.

BRASIL. Ministério da Agricultura e Reforma Agrária. Secretaria Nacional de Defesa Agropecuária. Departamento Nacional de Produção Vegetal. Coordenação de Laboratório Vegetal. Regras para Análise de Sementes. 1992. 365 p.

CUNHA, C.S.M.; TILLMANN, M.A.A.; VILLELA, F.A.; DODE, L.B.; BALERINI, F. Comparação de métodos na deteç̧ão de sementes de soja geneticamente modificada resistente ao glifosato. Revista Brasileira de Sementes, v.27, n.1, p.167-175, 2005.

FUNGUETTO, C.I.; TILLMANN, M.A.A.; VILLELA, F.A.; DODE, L.B. Detecção de sementes de soja geneticamente modificada tolerante ao herbicida glifosato. Revista Brasileira de Sementes, v.26, n.1, p.130-138, 2004.

GOGGI, A.S.; STAHR, M.G. Roundup ${ }^{\mathrm{TM}}$ pre-emergence treatment to determine the presence of the Roundup Ready ${ }^{\mathrm{TM}}$ gene in soybean seed: a laboratory test. Seed Technology, v.19, n.1, p.99-102, 1997.

KLEBA, J.B. Riscos e benefícios de plantas transgênicas resistentes a herbicidas: o caso da soja RR da Monsanto. Cadernos de Ciência \& Tecnologia, v.15, n.1, p.9-42, 1998. 
KRUSE, N.D.; TREZZI, M.M.; VIDAL, R.A. Herbicidas inibidores da EPSPS: revisão de literatura. Revista Brasileira de Herbicidas, v.1, n.2, p.139-146, 2000.

MARCOS FILHO, J. Fisiologia de sementes de plantas cultivadas. Piracicaba: FEALQ, 2005. 495p.

MENEZES, S.M.; TILLMANN, M.A.A.; DODE, L.B.; VILLELA, F.A. Detecção de soja geneticamente modificada tolerante ao glifosato por métodos baseados na atividade de enzimas. Revista Brasileira de Sementes, v.26, n.2, p.150155, 2004.

MIRANDA, D.M.; TILLMANN, M.A.A.; BALERINI, F.; VILLELA, F.A. Bioensaios na deteç̧ão e quantificação de sementes de soja geneticamente modificada resistente ao glifosato. Revista Brasileira de Sementes, v.27, n.1, p.93103, 2005.

MIRANDA, D.M.; TILLMANN, M.A.A.; NOLDIN, J.A.; BALERINI, F. Bioensaio em casa-de-vegetação na detecção e quantificação de sementes de soja geneticamente modificada. Revista Brasileira de Sementes, v.28, n.1, p.187-192, 2006.

PADGETTE, R.; KOLACZ, K.H.; DELANNAY, X.; RE, D.B.; LAVALLEE, B.J.; TINIUS, C.N.; RHODES, W.K.; OTERO, I.; BARRY, G.F.; KISHORE, G.M. Development, identification and characterization of a glyphosate-tolerant soybean line. Crop Science, v.35, p.1451-1461, 1995.

PEREIRA, W.A.; DEL GIÚDICE, M.P.; CARNEIRO, J.E.S.; DIAS, D.C.F.S.; BORÉM, A. Fluxo gênico em soja geneticamente modificada e método para sua detecção. Pesquisa Agropecuária Brasileira, v.42, n.7, p.999-1006, 2007.

TILLMANN, M.A.A.; WEST, S. Identification of genetically modified soybean seeds resistant to glyphosate. Scientia Agricola, v.61, n.3, p.336-341, 2004.

TORRES, A.C.; NASCIMENTO, W.M.; PAIVA, S.A.V.; ARAGÃO, F.A.S. Bioassay for detection of transgenic soybean seeds tolerant to glyphosate. Pesquisa Agropecuária Brasileira, v.38, n.9, p.1053-1057, 2003. 